ARTIGOS - ARTICLES

\title{
Manoel Ferreira de Araújo Guimarães (1777-1838): elementos necessários para uma revisão da História da Matemática no Brasil
}

\author{
Paulo Henrique Trentin \\ Professor Doutor - Fundação Educacional Inaciana - São Paulo (FEI - Departamento de Matemática) \\ trentin@fei.edu.br
}

Recebido em 21/04/2016. Aprovado em 04/07/2016.

Como citar este artigo: Trentin, Paulo Henrique. "Manoel Ferreira de Araújo Guimarães (1777-1838): elementos necessários para uma revisão da História da Matemática no Brasil”. Intelligere, Revista de História Intelectual, São Paulo, v. 3, n 1 [4], p. 78-98. 2017. ISSN 2447-9020. Disponível em < http://revistas.usp.br/revistaintelligere>. Acesso em dd/mm/aaaa.

Resumo: O presente artigo caracteriza aspectos sobre Manoel Ferreira de Araújo Guimarães do seu nascimento em 1777 à sua chegada a Portugal, para a conclusão de seus estudos. Traz apontamentos referentes a sua formação. Observa os apontamentos em publicações brasileiras do período relativas a História da Educação e a História da Matemática Brasileira, que serviram como referências para afirmar que se faz necessária uma revisão historiográfica. A base para esta afirmação, situa-se nas análises dos escritos que mencionam as identidades, atuações e os papéis que marcaram a vida de Manoel Ferreira de Araújo Guimarães.

Palavras-chave: História da Ciência, História da Educação Matemática, História da Matemática Brasileira - Manoel Ferreira de Araújo Guimarães

\section{Manoel Ferreira de Araújo Guimarães (1777-1838): necessary elements for a review} of the History of Mathematics in Brazil

\begin{abstract}
This article aims to feature aspects of Manoel Ferreira de Araújo Guimarães since born at 1777 until his arrival in Portugal, for the completion of their studies. Brings notes regarding his training. Observes the notes in the period Brazilian publications on the History of Education and the History of Mathematics Brazilian, who served as references to affirm that a historiographical review is necessary. The basis for this assertion lies in the analysis of the writings that mention the identities, actions and roles that marked the life of Manoel Ferreira de Araújo Guimarães.
\end{abstract}

Keywords: History of Science - History of Mathematics Education - History of Brazilian Mathematics - Manoel Ferreira de Araújo Guimarães. 


\begin{abstract}
[...] pela primeira vez, o país [Brasil] tinha consciência de estar estruturando uma cultura nacional. Veja-se, por exemplo, o valor de testemunho de dois fatos aparentemente desconexos: em 1814, funda-se o seminário de Jacuecanga, destinado à educação de meninos pobres, e a Impressão Régia publica os Elementos de Astronomia de Manoel Ferreira de Araújo Guimarães (1777-1838).
\end{abstract}

Wilson Martins ${ }^{1}$

\title{
Introdução
}

Notamos na última década uma quantidade considerável de publicações que abordam as contribuições que Manoel Ferreira de Araújo Guimarães² deixou para a Institucionalização do Ensino da Matemática no Brasil e para a História da Ciência Matemática Brasileira.

Neste artigo pretendemos, além de apresentar o estado da arte no que se refere as publicações referentes a Araújo Guimarães, retroceder ao período do seu nascimento, em 1777, à sua chegada a Portugal para completar seus estudos.

No ano de 2005, quando elaborávamos o texto da dissertação de mestrado para a defesa, pela primeira vez identificamos a chamada "primeira publicação destinada ao ensino de matemática com a instalação da família real no Brasil". 3Percebemos que os textos que tratam da história da matemática brasileira citam esta tal obra de Legendre editada por Araújo Guimarães, como uma tradução que não logrou êxito.

Não satisfeitos com a leitura que fizemos, decidimos buscar tal livro, pois pretendíamos conhecer o trabalho e checar que "mera" tradução foi esta, inserindo alguns comentários e impressões no texto da dissertação - ideia foi deixada a margem por sugestão da orientadora da dissertação a época.

Fomos surpreendidos quando identificamos que não se tratava de uma simples tradução do francês para o português. O original de Legendre, intitulado em português como Elementos de Geometria, havia sido editado, com cuidado, por alguém que mostrou possuir conhecimentos consistentes acerca do que se devia e podia ensinar com o uso do texto de Legendre à época. Há no texto toda a compreensão e o entendimento das necessidades da formação de pessoas para a defesa do território brasileiro, deixadas pelo editor Araújo Guimarães. Entendemos que o tradutor e sua tradução mereceriam uma análise cuidadosa, pois Araújo Guimarães, o "mero tradutor", fora deixado à margem pelos historiadores da Educação Matemática Brasileira.

Concluímos a dissertação e meses depois retomamos as análises que consideravam as produções de Araújo Guimarães identificando os pontos relevantes que justificavam a uma releitura.

\section{Alguns escritos relativos a História da Educação Matemática Brasileira}

Iniciamos pelo artigo publicado em 1996 por Circe Mary Silva da Silva intitulado $A$ V ariação dos Triângulos Esféricos de Manuel Araújo Guimarães, primeiro impresso de Matemática, no Brasil, após a

\footnotetext{
${ }^{1}$ Wilson Martins, História da Inteligência Brasileira, Vol. II. (São Paulo, Cultrix. Ed. da Universidade de São Paulo, 1977$), 54$.

${ }^{2}$ A partir deste ponto chamaremos Manoel Ferreira de Araújo Guimarães de Araújo Guimarães, opção que temos adotado deste do primeiro trabalho que publicamos sobre este personagem em 2007.

3 Identificamos esta forma de considerar a tradução que Araújo Guimarães realizou da obra de Adrien Marie Legendre intitulada Elementos de Geometria, no início do século XIX, para o uso na Academia Real Militar do Rio de Janeiro, nas seguintes referências: (1) Jairo de A. Lopes, Livro Didático de Matemática: concepção, seleção e possibilidades frente a descritores de análise e tendências em Educação Matemática,(São Paulo, FE Unicamp, 2000); (2) Wagner Rodrigues Valente, Uma História da Matemática Escolar No Brasil (1730-1930).(São Paulo, Editora Annablume, 1999).
} 
liberação da imprensa em 1810, ${ }^{4}$ notemos que praticamente este é um trabalho que retoma a análise do período como quase 20 anos.

O artigo destaca em suas análises que Araújo Guimarães, de fato, tinha domínio sobre das discussões e possibilidades da utilização de ferramentas matemáticas. Como exemplo, citamos a utilização do cálculo diferencial nas inferências que realizou ao explorar os triângulos esféricos. As considerações que Araújo Guimarães imprimiu no artigo em questão foram incorporadas à outra de suas obras destinada ao ensino da Astronomia.

Do artigo de Silva, de 1996, passamos para o artigo nominado como A Cultura Científica e a Gazeta do Rio de Janeiro (1808-1821), ${ }^{5}$ de José Carlos de Oliveira, no qual há referência as contribuições de Araújo Guimarães a constituição da Imprensa no Brasil. O autor considera relevante a constituição de uma imprensa e o surgimento de uma editoração que cuidasse da apresentação de aspectos relativos as ciências, o que o autor considerou ser a formação de uma cultura científica em terras brasileiras.

Para Oliveira, Araújo Guimarães desempenhou um papel relevante nesse sentido como um editor, com formação em matemática, professor, tradutor e autor de obras destinadas ao ensino das ciências, oferecendo publicações que alinhava o restrito grupo de leitores ao que se discutia sobre ciência à época, início do século XIX. Além de oferecer trechos de poemas e outros gêneros publicados originalmente em Latim, os quais ele fazia questão de destacar sua fidelidade a língua materna da produção. Aliás, não são poucas as menções que identificamos - e que, in loco, pudemos averiguar- relativas ao trabalho como tradutor que realizou durante toda sua vida.

Após estes artigos há um período de recesso, de esquecimento, no que se refere aos trabalhos de Araújo Guimarães, retomado próximo ao centenário comemorativo da chegada e instalação da família Real no Brasil, por volta do ano de 2008. Ressurgem escritos relativos ao período. Notamos dez anos sem que houvesse algo que, direta ou indiretamente, tratasse das contribuições dadas por Araújo Guimarães. É oportuno dizer que, neste período, as obras que tratavam da abordagem de aspectos da História da Matemática (ou da Educação Matemática) Brasileira, nem ao menos se preocuparam em incorporar o que os dois artigos que mencionamos destacaram relativamente ao período histórico e a Araújo Guimarães.

A partir de 2008 algumas reflexões, relativas a atuação de Araújo Guimarães, são retomadas. ${ }^{6} \mathrm{O}$ grupo de pesquisa em Educação Matemática na Universidade Federal do Rio de Janeiro realizou um estudo da obra Elementos de Geometria, repaginando e republicando-a. Além da publicação da tradução de Araújo Guimarães, não identificamos que o grupo de pesquisa tenha aprofundado qualquer estudo relativo a vida e obra de Araújo Guimarães. ${ }^{7}$

Em Portugal, também, identificamos pesquisadores interessados nos trabalhos de Araújo Guimarães. Um deles é Luis Miguel Carolino, com um artigo de título Manoel Ferreira de Araújo Guimarães, a Academia Real Militar do Rio de Janeiro e a definição de um gênero científico no Brasil em inícios do

\footnotetext{
${ }^{4}$ Circe Mary Silva da Silva, "A Variação dos Triângulos Esféricos de Manuel Araújo Guimarães, primeiro impresso de Matemática, no Brasil, após a liberação da imprensa em 1810", Revista da Sociedade Brasileira de História da Ciência, [vol.]15, (1996) (53-66).

${ }^{5}$ José Carlos de Oliveira, "A Cultura Científica e a Gazeta do Rio de Janeiro (1808-1821) ", Revista da Sociedade Brasileira de História da Ciência, [vol.]17, (1997) (29-58).

${ }^{6}$ Neste sentido pode-se consultar as comunicações que realizamos nos encontros e simpósios para cumprimento dos créditos de doutoramento, como por exemplo, "Alguns Textos de História em Livros de Matemática: Uma primeira aproximação", História da Ciência e Ensino, [vol.]3(2011) (1-6); "Documentos para a História da Ciência no Brasil”", comunicação apresentada na II Jornada de História da Ciência e Ensino, em julho de 2009.

${ }^{7}$ A obra foi reeditada pelo professor Luiz Carlos Guimarães do Instituto de Matemática da Universidade Federal do Rio de Janeiro, adquirimos um exemplar em uma das visitas que realizamos ao Acervo de Obras Raras da UFRJ.
} 
século $X I X,{ }^{8}$ que no nosso entendimento ratifica a importância da atuação de Araújo Guimarães para a institucionalização das Ciências no Brasil.

Cabe destacar que a nossa perspectiva relativa a institucionalização não cumpre as etapas que tradicionalmente se espera, ou seja, a da formação de um grupo de pessoas que fundam uma área do conhecimento e que a partir de então dão vazão aos trabalhos inéditos, fomentando as investigações na área. Compreendemos as limitações da época, do público consumidor de publicações científicas, da falta de pares para a consolidação de um diálogo, do isolamento geográfico do Brasil em relação aos centros reconhecidamente produtivos, como por exemplo Inglaterra e França. Mas, dito por um português, como no caso Carolino que investigou nos arquivos portugueses possíveis contribuições deixadas por Araújo Guimarães é que o nosso argumento se reforça.

Para Carolino, a singularidade das produções, ideias e conhecimentos relativos as discussões científicas do início do final do século XVIII e início do século XIX, se refletem quando Araújo Guimarães elabora e disponibiliza o texto destinado ao ensino de Astronomia para o uso na Academia Real Militar do Rio de Janeiro. ${ }^{9}$ Para o pesquisador, o texto é um exemplo do nível de conhecimento, resultado da experiência adquirida por Araújo Guimarães, em Portugal, como tradutor, além do domínio do latim e do francês.

Há, também, em Portugal a produção de Luis Manuel Ribeiro Saraiva denominada Manoel Ferreira de Araíjo Guimarães (1777-1838): From the Navy Royal Academy to the Royal Military Academy of Rio de Janeiro, ${ }^{10}$ com o relato da vida e da obra de Araújo Guimarães de sua estada em Portugal até sua passagem pela Academia Real Militar do Rio de Janeiro. O autor considera as produções e a atuação de Araújo Guimarães, principalmente como editor de A Gažeta do Rio de Janeiro, de O Patriota e de O Espelho.

Saraiva reafirma o que observamos em relação ao importante trabalho como tradutor de obras francesas para o ensino das matemáticas que Araújo Guimarães realizou. Inicialmente para o uso em Portugal e depois no Brasil.

Por fim, o pesquisador considera significativa para a História da Matemática o número de traduções e textos disponibilizados no Brasil e Portugal. Para o autor houve um ganho qualitativo em termos de divulgação de conhecimentos matemáticos com o trabalho de tradução e a disponibilização de obras produzidas em reconhecidos centros de estudos matemáticos da época, como França e Inglaterra. Neste sentido é que ele destaca a contribuição de Araújo Guimarães.

Voltando as produções brasileiras sobre Araújo Guimarães, a pesquisadora Ligia Arantes Sad, em seu artigo intitulado: Rastros do ensino de cálculo diferencial e integral nas décadas iniciais da Academia Militar do Rio de Janeiro. ${ }^{11}$ A partir de registros documentais, ela apresenta um exame de aspectos deixados a respeito do ensino de cálculo e das suas representações.

Para a autora, as representações são necessárias aos que se interessam pela história da matemática na primeira metade do século XIX. Sad considera a presença, nas obras traduzidas para o ensino do cálculo, de características herdadas pelas transições epistemológicas dos desenvolvimentos do cálculo, como, por exemplo, os métodos com base em quocientes de razões entre diferenciais transladadas em termos de séries infinitas ou de somas finitas, sem a passagem explícita pela

\footnotetext{
${ }^{8}$ Luis Miguel Carolino, "Manoel Ferreira de Araújo Guimarães: a Academia Real Militar do Rio de Janeiro e a definição de um gênero científico no Brasil em inícios do século XIX”, Revista Brasileira de História, [vol.]3, 64, (2012).

${ }^{9}$ Manoel Ferreira de Araújo Guimarães, "Elementos de Astronomia para o uso dos alumnos da Academia Real Militar", (Rio de Janeiro: Impressão Régia, 1814).

${ }^{10}$ Luis Manuel Ribeiro Saraiva, "Manoel Ferreira de Araújo Guimarães (1777-1838): From the Navy Royal Academy to the Royal Military Academy of Rio de Janeiro", Revista Brasileira de História da Matemática, [vol.]11, (2011) (77-106).

${ }^{11}$ Ligia Arantes Sad, "Rastros do ensino de cálculo diferencial e integral nas décadas iniciais da Academia Militar do Rio de Janeiro", Revista Brasileira de História da Matemática, [vol.]11, 21, (2011) (45-67).
} 
definição de limite. Indiretamente a pesquisadora oferece subsídios para a compreensão da dimensão didática estabelecida para os estudos das matemáticas na Academia Real Militar. O período abarca a atuação de Araújo Guimarães na Academia Real Militar do Rio de Janeiro.

Há algumas comunicações e atividades de produção relativas a Araújo Guimarães que não estão explícitas no texto de Sad. Porém o trabalho indica, antes de qualquer outra coisa, o interesse retomado em relação a Academia Real Militar.

Identificamos nos artigos que parte da motivação tem relação com a data comemorativa do centenário de instalação da Família Real no Brasil, em 2008. Os trabalhos, especificamente relativos a Araújo Guimarães, diferentemente do que tínhamos, buscaram apresentar uma releitura do período, propondo uma imersão centrada em documentos, evitando análises extensivas sem profundidade, carregadas de vícios reproduzidos em outras produções. Um exemplo disto é o que no início deste texto destacamos relativamente ao entendimento de que Araújo Guimarães fora um mero tradutor de uma das obras de Adrien Marie Legendre.

Entendemos que Araújo Guimarães mereça ser incluído entre os ilustres brasileiros, que por vezes são entendidos como importantes para a institucionalização da ciência matemática brasileira, seja no que se refere ao ensino ou a pesquisa. Mas, há uma pergunta que ainda resta-nos responder neste texto: 'Qual o percurso de nossa personagem do nascimento até a chegada a Portugal"?

Para responder a esta pergunta procuraremos caracterizar o período compreendido entre a parte final do século XVIII e o início do século XIX, da vida social brasileira para uma família de um negociante, ou comerciante, baiano de nome Manoel Ferreira de Araújo, o pai de Araújo Guimarães.

\section{O caminho do menino Araújo Guimarães até Portugal}

Optamos por circunstanciar aspectos da infância de Araújo Guimarães sem registrar curiosidades ou ilações que pouca certeza nos daria. Aliás, não identificamos pontualmente nada escrito relativamente sobre a infância de Araújo Guimarães. Assim, optamos por identificar quais as circunstâncias que favoreceram à que Araújo Guimarães pudesse chegar a Portugal. Para tanto, entendemos ser adequado tratar o primeiro provedor, seu pai. Mas o que foi o comércio no período colonial brasileiro?

Nas palavras de Prado Júnior, o comércio do período colonial realizava-se com gêneros tropicais e metais preciosos para o mercado internacional. ${ }^{12}$ Ou seja, de certa forma a que se considerar a existência de um comércio interno e um externo. O comércio exterior era marítimo, uma vez que as fronteiras terrestres eram pouco povoadas. Porém, diz o pesquisador, que algumas ações como contrabandos de muares existiam e chegavam pelas fronteiras do sul da colônia.

Em outras fronteiras, como do alto Amazonas havia a troca de manufaturas, em vias de mão dupla, entre os produtos espanhóis, portugueses e dos povos ribeirinhos ${ }^{13}$.

Pudemos identificar que a descoberta do ouro foi a mais importante consequência das expedições que partiram de São Paulo para o interior. A corrida ao ouro atraiu milhares de pessoas provenientes das plantações do litoral, além de novas levas de imigrações de Portugal. Além do

${ }^{12}$ Caio Prado Júnior, Formação do Brasil Contemporâneo, (São Paulo: Editora Brasiliense, 1994), 228-36.

${ }^{13}$ Ibid, 229. 
mais, houve o crescimento da criação de gado no interior, para prover carne e couro para os centros de mineração e o surgimento de novas cidades no que é hoje o estado de Minas Gerais.

A crescente extração de ouro no Brasil, entre 1770 e 1800, favoreceu o estabelecimento um ciclo de desenvolvimento importante, que teve relação com os acontecimentos não só na colônia como na Europa. Muito embora o ouro fosse controlado por Portugal e embarcado para Lisboa, ele acabava por pararem Londres. Os produtos ingleses dominaram o mercado brasileiro, acabando com qualquer chance de competição e desencorajando qualquer atividade industrial no Brasil.

O cenário comercial, nos escritos de Prado Júnior, merecia indignação. Prado Júnior reforça esta afirmação no trecho a seguir, apresentando o relato de um português que

viajou a negócios para a Inglaterra e Irlanda, e tão escandalizado ficou com o cônsul de seu país e a maior casa portuguesa de comércio em Londres, Liverpool e mais portos saíam regularmente navios com pretexto de irem hostilizar os franceses (...) ou para pesca da baleia, mas na realidade carregados de mercadorias que se destinavam ao Brasil; e traziam de volta os produtos da colônia. ${ }^{14}$

Neste período de atuação como comerciante, do pai de Araújo Guimarães, além do contrabando Inglês, havia um caminho de mão dupla entre a colônia e a metrópole, que esquematicamente tratamos de reproduzir, com base no modelo oferecido por Prado Júnior temos: ${ }^{15}$

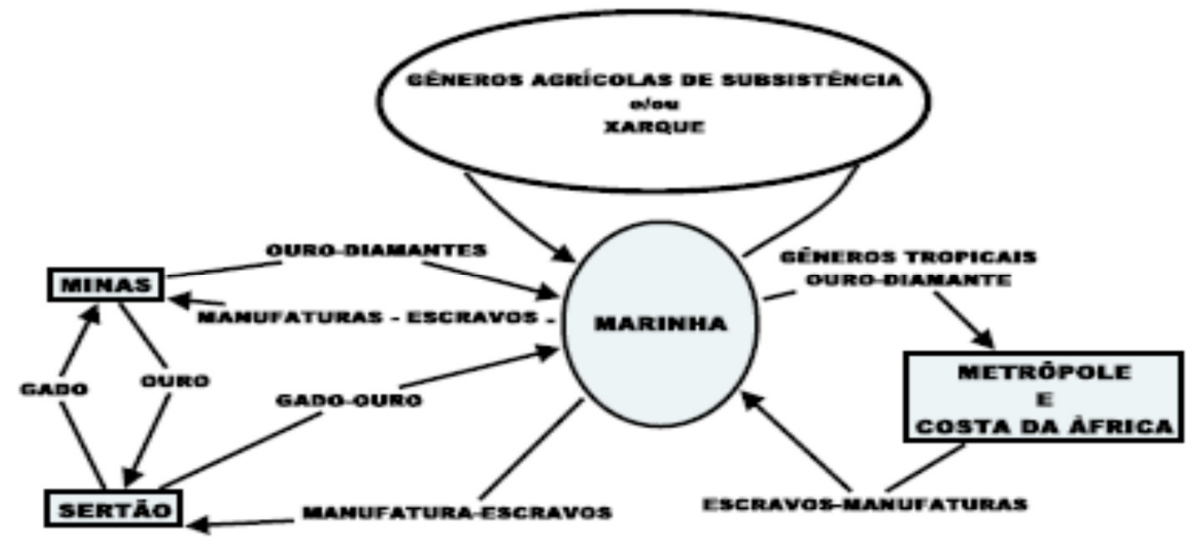

figura 1r modelo segundo Calo Prado Júntor das relaçōes comerciaìs no periodo coloníal brasileiro

Nas palavras de Pombo,

Dês do estabelecimento dos primeiros colonos, compreende-se como se não podia prescindir de certas relações, não diremos propriamente de comércio, mas de tráfico entre a vasta possessão portuguesa na América e a respectiva metrópole. De lá vinham manufaturas de que os imigrantes não podiam pri-

${ }^{14} \mathrm{Ibid}, 231$

${ }^{15}$ Ibid, 234. 
var-se tão cedo; e daqui se mandavam gêneros da terra que tinham preço lá na Europa. ${ }^{16}$

Manoel Ferreira de Araújo foi homem deste tempo e possivelmente, participava mediando entre o Sertão e a Marinha a negociação de ouro e gado e da Marinha para o Sertão, escravos e manufaturas. Pelo que identificamos na reconstrução histórica que fizemos é muito provável que Manoel Ferreira de Araújo servisse diretamente o governo da Bahia, sem participar de tráficos ou, ao menos, se envolver com tais práticas. Pombo nos apresenta os comentários do Marquês do Lavradio que reforçam esta nossa proposta:

(...) o maior dos entraves opostos ao desenvolvimento do comércio e da riqueza em geral, [é] o fato de só haver na praça do Rio não pròpriamente comerciantes, mas simples comissários que se limitavam a receber artigos europeus remetidos pelos comitentes, e a enviar para a Europa os gêneros que estes lhe pediam. ${ }^{17}$

Não nos interessa aprofundar as discussões em relação as dificuldades que identificamos, seja em relação as precárias vias para o deslocamento ou em relação a distância entre os centros destinados ao comércio, além dos entraves que se opunham à atuação dos comerciantes, então chamados de comissários, como, por exemplo, a concorrência com os estrangeiros. Nos interessa apontar que pouco o comerciante Manoel Ferreira de Araújo poderia acumular de rendimentos que permitiriam a manutenção de seu filho Araújo Guimarães em seus estudos na metrópole.

Aliás, já se faz necessário passar às considerações relativas a educação inicial que recebeu Araújo Guimarães. Nesta direção, identificamos que o ano de 1777, além de ser lembrado pelo Jornal O Patriota ${ }^{18}$ como o ano da morte de quarenta soldados por índios Guaicurus numa disputa por terras na região centro-oeste do Brasil, foi o ano do nascimento de Araújo Guimarães, na Bahia, no dia 05 de março.

O filho de Manoel Ferreira de Araújo, comerciante, e de Maria do Coração de Jesus, Araújo Guimarães, então com sete anos, foi matriculado na escola de primeiras letras sob a administração do padre José Lopes. Este padre, da Companhia de Jesus, ensinava teologia, filosofia, retórica, gramática e, também, as chamadas primeiras letras. Essa escola, por volta de 1713, estava localizada na Igreja de Nossa Senhora da Madre de Deus, ao sul da capitania do Maranhão. Tal igreja passou ao domínio dos jesuítas, sem precisão de como e quando, transformando-se na escola que Araújo Guimarães frequentou, até sua ida para Portugal.

Há que se considerar que o ensino das matemáticas nos colégios da Companhia de Jesus, atrelava-se ao da física e enfatizando a formação nas letras. O domínio do latim era uma condição necessária. Contudo, resta-nos uma questão: 'O que levou Araújo Guimarães, mais tarde, a escolher o estudo da Matemática"?

Somos levados a pensar que, após os estudos iniciais, numa fase posterior frequentada por um número reduzido de alunos, em que havia lugar para as ciências como a física, a lógica, a ética e a metafísica, foi que Araújo Guimarães enveredou para estudos específicos que mais tarde o conduziram ao aprofundamento em Portugal, dando-lhe conhecimentos em trigonometria esférica e outras ciências que desembocariam, anos depois, nas produções que disponibilizou na Academia

\footnotetext{
${ }^{16}$ Rocha Pombo, História do Brasil., vol. VI-X (Rio de Janeiro: Benjamim de Aguila Editor, 2010).

17 Ibid, 220.

${ }^{18}$ O Patriota, Jornal Litterario, Político, Mercantil, etc. (Rio de Janeiro: Impressão Régia, 1813-14).
} 
Real Militar do Rio de Janeiro. ${ }^{19}$ Voltemos aos aspectos relativos à nossa personagem central nesse enredo.

Destacando-se como aluno e obtendo bons resultados, ele decide estudar línguas. Então, aos 11 anos passa a estudar latim com o professor Pedro Antonio Netto Cavalcanti e teve um ótimo desempenho como estudante. ${ }^{20}$ Araújo Guimarães era considerado genial no que se referia ao aprendizado de línguas. Destacou- se nos estudos do latim, mostrando facilidade para a imersão na língua a ponto de preparar traduções de textos disponibilizados pelos seus professores. Além do mais, mostrava-se interessado e com facilidade para o aprendizado das ciências. Estes atributos favoreceram a indicação para a continuação dos estudos em Portugal. Porém, como anteriormente consideramos, as reservas financeiras de seu pai permitiam que apenas chegasse a Portugal e se mantivesse por um curto período. Araújo Guimarães decidiu apostar em sua capacidade e dedicação, para manter-se em Portugal, e no apoio de sua tia Izabel Narciza.

Em julho de 1791, então com 14 anos, Araújo Guimarães transferiu-se para Portugal para morar com tia Izabel Narcisa. Narcisa foi muito importante durante principalmente os primeiros anos em Portugal. Encontramos uma série de passagens em que há menção à atenção que ela dedicava a Araújo Guimarães, cuidando de sua alimentação, suas roupas, além de ceder-lhe abrigo.

Araújo Guimarães não levou seu passe de latim, que avalizava seus conhecimentos e permitiria prosseguir seus estudos. Ele, assim, teve que matricular-se nas aulas de latim com o professor Manoel Rodrigues Maia, em outubro de 1791. Logo nas primeiras aulas o professor Maia percebeu qual talentoso era Araújo Guimarães e decidiu conceder uma ocupação que lhe renderia alguma remuneração, pois sabia de suas dificuldades. Pediu a Araújo Guimarães que traduzisse algumas obras em latim. É oportuno dizer que, Araújo Guimarães, por vontade própria e simultaneamente, estudara grego, italiano e francês. Isto o tornara um conhecedor de línguas nas quais importantes trabalhos para o ensino das matemáticas eram produzidos.

O país que recebeu o jovem com 14 anos havia iniciado em 1772 a reforma da Universidade de Coimbra e, nesse mesmo ano, fundava a Faculdade de Matemática, pois, acreditava-se, que com isso Portugal pudesse atingir um grau de desenvolvimento, no que se referia ao conhecimento científico, equivalente ao que se encontrava a França e a Inglaterra, nesse mesmo período. Destacamos que a proposta era estudar Trigonometria Esférica, Navegação Teórica e Prática e rudimentos de Tática Naval.

Neste período de preparação de Araújo Guimarães, que antecedeu seu ingresso na Universidade de Coimbra, aprimorando seus estudos em línguas e matemática, ele descobre que portava uma doença que comprometeria a sua saúde respiratória. Não identificamos uma classificação para o mal mas suspeitamos ser uma doença similar a tuberculose. Esta doença, de certa forma, trouxe-lhe uma sequência de vida com limitações, porém não impediu a conclusão aos 21 anos, então casado, do "Curso Matemático” na Academia Real dos Guardas-Marinha, 180121.

Ora, temos repertório para nos alongarmos em mais algumas dezenas de páginas, contando os caminhos e descaminhos de Araújo Guimarães. A parte que vai do seu casamento ao seu retorno ao Brasil, porém pretendemos oferecer-lhes em outras publicações. Atendemos aos objetivos estabelecidos para este texto. Deixamos um trecho oferecido por Damasio, que corrobora com o que pensamos: "Assim que, para vingar semelhante esquecimento, e também para pagar

\footnotetext{
${ }^{19}$ Serafim Leite, História da Companbia de Jesus no Brasil, vol. 7 (Rio de Janeiro: IHGB, 1945).

${ }^{20}$ Antonio Joaquim Damasio, Biographia dos Brasileiros Distinctos por Armas, Lettras, Virtudes e etc., (Rio de Janeiro: IHGB, 1881), 378.

${ }^{21}$ Ibid, 379
} 
tributos a gratidão [...] o autor desta biographia [...] a offerece como uma medalha de escasso thesouro para suffragar [...] a memória de suas eminentes qualidades". 22

Note que já à época da publicação, Damasio queixava-se do esquecimento de ilustre personalidade. Nada diferente do que dissemos e o que temos ainda por considerar. Vejamos, a seguir, as notas nos textos destinados a História da Matemática Brasileira, que circulam neste século XXI, referindo a produção e Araújo Guimarães.

\section{Apontamentos relativos a trajetória de Manoel Ferreira de Araújo Guima- rães}

Consideramos relevante apresentar como alguns pesquisadores brasileiros inserem na História Araújo Guimarães, ou seja, que identidades atribuem a ele no cenário histórico de um modo geral. Isto, servirá para que possamos encerrar este primeiro material deixando exatamente no ponto que nos propusemos a chegada de Araújo Guimarães a Portugal.

Revisitando os trabalhos de Valente ${ }^{23}$ e Dynnikov ${ }^{24}$ verificamos que ambos citam o trabalho de Araújo Guimarães. Os autores inserem pequenas notas destacando que Araújo Guimarães é o responsável pela primeira tradução brasileira para o ensino de Matemática, ou que ele é o responsável pela primeira produção para a língua portuguesa da obra Éléments de Géométrie, de Adrien Marie Legendre.

As resumidas menções não diferem praticamente em nada em relação ao que identificamos nos textos selecionados de Silva ${ }^{25}$ e D'Ambrosio ${ }^{26}$, uma vez que há menção a Araújo Guimarães como o responsável pela primeira tradução para a língua portuguesa da obra de Legendre.

Vejamos um trecho em Valente relativo ao trabalho de Araújo Guimarães:

A tradução dos Elementos de Geometria de Legendre foi feita por Manoel Ferreira de Araújo Guimarães, que foi aluno e lente da Academia Real de Marinha de Lisboa e professor na Academia Real dos Guardas-Marinha no Brasil. [...] Guimarães, no preâmbulo do livro, depois de ressaltar a importância dos textos traduzidos contra "presumíveis sábios que olham com desprezo para semelhantes trabalhos", modestamente revela "Intimamente persuadido da pequenez de minhas forças, e tendo antes a fraqueza de confessar (...) julguei mais sensato trasladar o que eles ensinam do que cansar o leitor com minhas bagatelas. ${ }^{27}$

O texto de Valente mostra a importância dada à biografia de Legendre, deixando apenas algumas linhas para a apresentação de poucos apontamentos relativos à Araújo Guimarães que, aliás, mereceriam algum aprofundamento, pois a cópia da página da Tradução dos Elementos de Geometria é de 1837 e de Francisco Vilela Barbosa. No trecho anterior há duas frases que são comentários do tradutor Araújo Guimarães. Isso mostra que o pesquisador deva ter tido contato com a tradução realizada por Araújo Guimarães, porém pouco se aprofundou em relação aos

\footnotetext{
22 Ibid, 377.

${ }^{23}$ Wagner Rodrigues Valente, Uma História da Matemática Escolar no Brasil:1730-1930 (São Paulo: Annablume: Fapesp, 2007).

${ }^{24}$ Circe Mary Silva da Silva Dynnikov, A Matemática Positivista e sua difusão no Brasil (Espírito Santo: EDUFES, 1999).

${ }^{25}$ Clóvis Pereira da Silva. A Matemática no Brasil: História de Seu Desenvolvimento (São Paulo: Ed Edgard Blucher Ltda., 2003).

${ }^{26}$ Ubiratan D'Ambrosio, Uma História Concisa da Matemática no Brasil (São Paulo: Vozess, 2008).

${ }^{27}$ Ibid, 101-102.
} 
comentários que o tradutor deixou em relação ao tratado de trigonometria, ou quem sabe as considerações foram feitas a partir da tradução de Francisco Vilela Barbosa.

Evidentemente que sabemos não ser o trabalho de Araújo Guimarães o centro dos estudos da tese de Valente. Porém, sendo o foco de seus estudos as obras destinadas ao ensino de Matemática, e ainda destacando o trabalho de Legendre, pensamos fosse interessante uma revisão mais cuidadosa em relação ao trabalho do tradutor.

Dynnikov por centrar suas discussões na questão do positivismo presente na Academia Real Militar deixa também à margem as considerações específicas sobre o papel do tradutor da obra de Legendre, sua biografia ou, especificamente a sua obra. Mas, cabe salientar que a pesquisadora realizou alguns levantamentos acerca de Araújo Guimarães. Isso pode ser verificado em uma publicação que, a partir de outro trabalho, a pesquisadora trouxe uma menção à produção de Araújo Guimarães. Porém, percebemos que tal pesquisa não fora plenamente incorporada ao trabalho que analisamos. Como vemos a seguir:

Segundo Oliveira de Castro os folhetos denominados de "Variação dos triângulos esphericos" para uso da Academia Real Militar, Rio de Janeiro, na Imprensa Régia, 1812, por Manoel Ferreira de Araújo Guimarães (12 páginas), são cronologicamente, os primeiros e, ao mesmo tempo, os mais interessantes dos que foram escritos no país antes da independência. ${ }^{28}$

O trabalho que serviu de referência à Dynnikov, de Oliveira de Castro, intitulado $A M a$ temática no Brasil de 1992, refere-se a um livro praticamente de bolso que, também, não faz nenhuma menção que pudesse nos servir de referência para nosso trabalho de investigação. Notamos que a partir da menção de Oliveira Castro aos folhetos, citados no trecho acima, é que Silva elaborou o artigo que trouxe fragmentos sobre Araújo Guimarães.

Quando tratamos de analisar os textos de Silva ${ }^{29}$ e D'Ambrosio ${ }^{30}$ à procura de referências a respeito de Araújo Guimarães, identificamos que também não há nada de específico à importância das traduções, das contribuições, além de poucas referências ao que ele (Araújo Guimarães) representou de acordo com o específico recorte que propõem para suas obras.

Como exemplo, sob o título Os primeiros estudos matemáticos, na página 47, D’Ambrosio, registra que:

O translado da família Real para o Brasil esvaziou os movimentos de independência por razões óbvias. A família Real teve sensibilidade política para dar espaço para os nacionalistas manifestarem-se e a imprensa teve um papel nessa estratégia da política Real. Um bom exemplo dessa política Real é o aparecimento de uma revista, "O Patriota", fundada pelo matemático Manoel Ferreira de Araújo Guimarães, onde também se publicavam textos matemáticos. Araújo Guimarães havia publicado na Imprensa Régia, em 1810, o primeiro trabalho matemático impresso no Brasil. ${ }^{31}$

\footnotetext{
${ }^{28}$ Circe Mary Silva da Silva Dynnikov, "A Variação dos Triângulos Esféricos de Manuel Ferreira de Araújo Guimarães: primeiro impresso de Matemática, no Brasil, após a liberação da imprensa em 1810”', Revista da SBHC [vol.]5, (1996) (5366).

${ }^{29}$ Ibid.

${ }^{30}$ Ibid.

${ }^{31}$ Ibid, 47.
} 
Este trecho serve para ilustrar a busca pela primeira publicação matemática, seja sob qualquer ponto de partida. Esse é um fato que nos chama a atenção quase que em todas as produções que se destinem a tratar da história da matemática no Brasil. Além do mais, vemos que esse apontamento de D’Ambrósio vai ao encontro das referências que serviram às considerações de Silva ${ }^{32}$ que, anteriormente, destacamos.

Há considerações ao trabalho de Araújo Guimarães quando Silva trata da organização dos cursos na Academia Real Militar, a partir de 1809. Em relação a este tema considera Silva:

Contudo devemos registrar a preocupação dos organizadores dos cursos da Academia Real Militar quanto à qualidade e seriedade, levando-se em consideração os padrões científicos e culturais da época. [...] mesmo assim, foram feitas traduções e publicações de L. Euler, A. M. Legendre, S. F. Lacroix, N. L. Lacaille, dentre outros. Para algumas dessas traduções, muito contribuiu o professor Manoel F. de Araújo Guimarães, que se destacou como um dos intelectuais da época. ${ }^{33}$

O fragmento acima encerra as referências que destacamos em relação a Araújo Guimarães, quando recorremos a falar das obras destinadas a tratar da Ciência Matemática no Brasil, ou seja, o período em que a Família Real instala-se no Brasil. Porém, vamos registrar alguns predicados atribuídos a Araújo Guimarães e que nos guiaram durante a realização de nossa investigação, fosse com a intenção de realizar uma verificação ou para reescrever uma história a seu respeito.

D’Ambrosio refere-se a Araújo Guimarães como o Matemático que, em 1810, publica uma primeira obra em terras brasileiras. Valente tenta aprofundar um pouco na bibliografia do autor, destacando que ele (Araújo Guimarães) foi aluno e lente da Academia Real de Marinha de Lisboa e professor na Academia Real dos Guardas-Marinha no Brasil. Enquanto que para Clóvis Pereira da Silva, Araújo Guimarães contribuiu como tradutor de algumas obras, professor intelectual da época. ${ }^{34}$

Como temos insistido está caracterizado para os autores que tratam da história da matemática no Brasil que a Araújo Guimarães foi "mero" responsável pela tradução das obras de Legendre para o Português. Enquanto tratam Legendre como quem se destacou pela autoria de obras que foram reconhecidas e, por isso, traduzidas em outras línguas. Reafirmamos que não há, de modo evidente, um aprofundamento nas considerações das traduções realizadas por Araújo Guimarães, quando analisadas sob a luz dos textos que as inspirou. Bastaria debruçar sobre o original e a tradução para perceber alguns apontamentos que apresentaremos a seguir.

Araújo Guimarães dominava profundamente o Francês e o Latim, além de conhecer o assunto que discutia sobre ideias matemáticas como, por exemplo, o sistema de medida decimal, que Legendre adotou para a medição da circunferência, e o modo como o autor organizou seus textos. ${ }^{35}$

O prólogo do tradutor contém as referências relativas: (1) aos posicionamentos sobre a língua francesa, (2) aos matemáticos europeus de sua época, (3) ao papel do tradutor, (4) as discussões em torno do sistema adotado pelos franceses para mediar os ângulos e a circunferência. No

\footnotetext{
32 Ibid.

33 Ibid, 34 .

34 Ibid, 8-46.

${ }^{35}$ Adrien Marie Legendre, Elementos de Geometria, (Rio de Janeiro; Impressão Régia, 1809):3.
} 
prólogo ainda é possível identificar como Araújo Guimarães concebia a Matemática e, nas adequações que realizou, identificamos o modo como ele concebia o ensino de matemática. ${ }^{36}$

Devemos relacionar cada apontamento e cada referência, deixados nas traduções, com os episódios que identificamos no capítulo no qual tratamos sobre a vida do tradutor. Parece-nos ser necessário, nesse ponto, indicar algumas possíveis conexões entre aspectos de sua vida e as traduções de Legendre com as quais ele nos presenteou. Passemos então, aos aspectos que nos chamaram a atenção quando realizamos nossa investigação.

No prólogo do tradutor dos Elementos de Geometria, Araújo Guimarães afirmou que não cabia a ele fazer elogios à obra nem ao autor, pois todos os reconhecimentos já foram dados por pessoas como Lagrange e Lacroix, e que, segundo ele (tradutor) isso já era suficiente. Lembremonos de que Lagrange é um dos que assinaram com J. C. Borda a produção destinada a sedimentar as vantagens da escolha do sistema de medida decimal como referência na França. Enquanto Lacroix foi um dos que, tempos depois, disputaram com Legendre o mercado de livros destinados ao ensino de Geometria e que, além disso, tinha a preferência de Araújo Guimarães ${ }^{37}$.

Em outra passagem dos Elementos de Geometria, Araújo Guimarães discorreu acerca de seu trabalho de tradutor. Num primeiro momento, ele aponta para a responsabilidade que representa o trabalho de um tradutor e que não era reconhecido pelos que ignoravam sua dedicação por, especificamente em seu caso, ter sacrificado horas preciosas de seu descanso e de ter inclusive comprometido a saúde. Ele coloca-se como uma pessoa que tinha a função de trazer conhecimento científico aos que, de outro modo, não teriam a possibilidade de tê-los e escreveu:

Sei que muitos presumidos Sabios olhão com desprezo para semelhantes trabalhos, a que nunca se dedicarão, e dos quaes por consequência ignorão todo o pezo. Aquelle que sacrifica as horas de seu descanso a comunicar aos seus compatriotas conhecimentos que, sem elle, lhes serião vedados, ou ao menos pouco vulgares, se considera como hum servil copista, que não tem fadiga alguma, salvo a de transcrever as palavras do Author, empreza, segundo elles muito fácil. Eu não faço a minha apologia, nem a sátira delles. Contento-me com ser útil e lhes deixo o vão officio de declamadores. ${ }^{38}$

Vemos, no trecho acima, que o tradutor, além de ter se colocado como alguém que respeitaria fielmente o texto transcrevendo as palavras de Legendre, reconheceu que seu trabalho foi importante e não deveria ser considerado como algo de pouco importância. Para o tradutor sua produção representava uma forma de oferecer ao povo brasileiro uma obra de reconhecido merecimento na Europa. Araújo Guimarães tinha a dimensão exata do que representaria a tradução de Legendre para o ensino de Matemática no Brasil.

Cabe, nesse ponto, lembrar que quando embarcou da Bahia em 1791, ele desejava ter se dirigido à Universidade de Coimbra, mas não pode devido as limitações financeiras de sua família. Tempos depois, casado e com uma família para manter, só conseguiu realizar seu desejo por ter recebido uma bolsa do governo português, na Academia Real dos Guardas-Marinha. Ainda aluno, dando aulas para manter-se e complementar a ajuda do governo, Araújo Guimarães combinou seu domínio do Latim e do Francês e em 1800 vislumbrou a possibilidade de elaborar traduções. Essa foi uma atividade que realizou praticamente a vida toda, traduzia obras de referência, principalmente para as que se relacionavam ao ensino da matemática.

\footnotetext{
${ }^{36}$ Ibid, 3-4.

${ }^{37}$ Ibid, 373

${ }^{38}$ Adrien Marie Legendre, Elementos de Geometria, (Rio de Janeiro; Impressão Régia, 1809):3.
} 
Então, em 1800 a tradução da obra de La Caille, que era uma referência na academia portuguesa em que estudava, lhe rendeu a confiança de Dom Rodrigo de Souza Coutinho. Isso nos permitiu afirmar que Araújo Guimarães não era um iniciante, ou apenas um indicado para realizar o trabalho de tradução de Legendre por amizades e bons relacionamentos. Ele já dispensava qualquer apresentação, pois acumulava a experiência de publicações e de regência de aulas de matemática na Bahia e em Portugal, havia pelo menos nove anos.

As traduções que analisamos de Araújo Guimarães não se limitaram a trazer as ideias postas pelo autor Legendre. O tradutor demonstrou conhecer as fontes que conduziram Legendre à constituição de seu material. Como consta no prólogo, ele deixou evidente como Legendre optou por organizar o texto dos Elementos de Geometria. Assim, após falar da organização dos livros I, II e III, Araújo Guimarães registrou que:

O livro $4 .^{\circ}$ trata do Polygonos regulares e da medida do circulo. Dois lemmas servem de base a esta medida que he demonstrada à maneira de Archimedes. Seguem-se dois methodos de aproximação, hum dos quaes he de Jacob Gregory. ${ }^{39}$

Notamos três referências no trecho acima. Uma em relação a dois Lemas que, segundo entendia-se na época, serviam como uma verdade que se empregava e que subsidiava a demonstração de um Teorema ou a solução de um problema.

Um dos Lemas enunciava que toda linha curva poligonal que envolvesse de um a outro extremo a linha convexa AMB seria mais comprida que a linha envolvida AMB. De acordo com a representação abaixo, retirada da obra de Legendre.

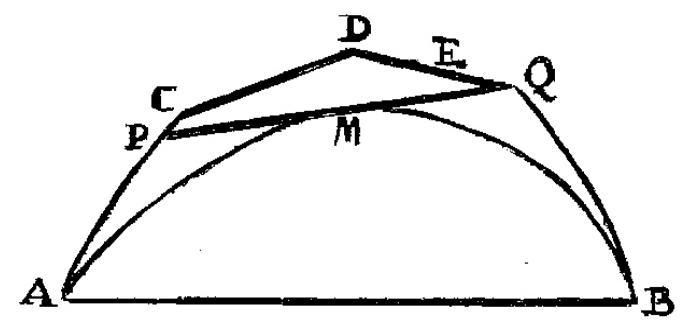

Figura1: Desenho de número 162, copiada da obra "Éleménts de Geométrie" de A. M. Legendre

O outro Lema enunciava que o triângulo $\mathrm{CAB}$ era equivalente ao triângulo isóscele DCE, o qual tinha o mesmo ângulo $\mathrm{C}$, e cujo lado $\mathrm{CE}$ ou $\mathrm{CD}$ representava a média proporcional entre $\mathrm{Ca}$ e CB. Além do mais, se o ângulo $\mathrm{CAB}$ fosse reto, a perpendicular CF, baixada sobre a base do triângulo isósceles seria média proporcional entre o lado CA e a "semissoma" dos lados CA e CB, como ilustra a figura a seguir:

\footnotetext{
${ }^{39}$ Ibid, 4.
} 


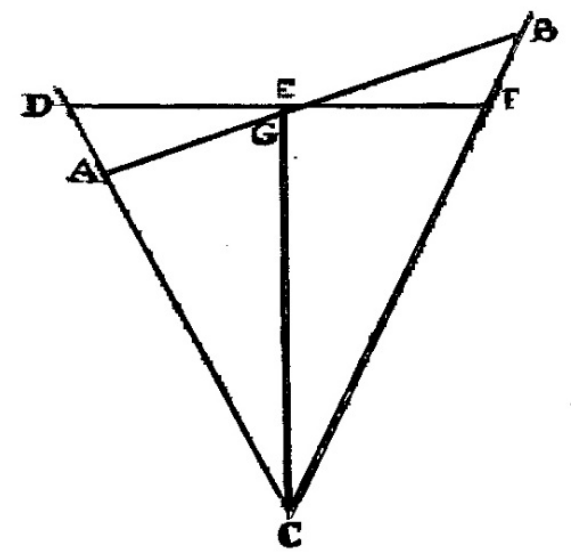

Figura 2: Desenho de número 170, copiada da obra "Éleménts de Geométrie" de A. M. Legendre

Vemos também na citação as menções a Gregory e a Arquimedes. Isso reforça nossa afirmação de que o tradutor tinha domínio matemático suficiente para apontar o que Legendre consultara e os encaminhamentos que utilizou nas demonstrações que deixou. Identificamos dois trabalhos que deram a dimensão acerca do que Arquimedes e Gregory estudavam e que formaram a base para Legendre. Gregory, um escocês que viveu no século XVII, foi quem ampliou os resultados de Arquimedes acerca da quadratura da parábola, a quadratura de hipérboles e elipses. ${ }^{40}$

Fizemos questão de mencionar o trecho do livro IV, relativo aos polígonos e às medidas do círculo, conforme apresentou Araújo Guimarães, para exemplificar que ele foi cuidadoso ao apresentar o que o autor da obra apontou, sem inclusões ou modificações significativas. O que notamos em relação a essa parte é que Araújo Guimarães cuidou de mencionar as referências utilizadas por Legendre e comentar, por exemplo, as relações com a obra de Euclides. O que nos permite dizer que a crítica aos Elementos de Euclides, como referência para o ensino de Matemática na França, não foi suficiente para que Legendre o abandonasse por completo. Nos comentários de Araújo Guimarães em relação aos Elementos de Geometria de Legendre, escreveu que:

O Livro $5^{\circ}$ contém as propriedades dos planos e dos ângulos sólidos... O $6^{\circ}$ trata dos polyedros. Este livro he escrito de hum modo inteiramente novo. $\mathrm{O} 7^{\circ} \mathrm{He}$ hum tratado resumido da esfera e dos triângulos esféricos. $\mathrm{O}$ appendice aos livros $6^{\circ}$ e $7^{\circ}$, tem por objecto os polyedros regulares; matéria tratada por Euclides com muita extensão. ${ }^{41}$

No trecho vemos a menção ao fato de que Euclides foi mais extenso em suas considerações a respeito dos poliedros regulares. O modo a que se referiu o tradutor, como foi escrito o livro VI, indicou que o encaminhamento das discussões e as notas, que Legendre incluiu em edições posteriores a de 1794, não tinham a mesma dimensão dada por Euclides ${ }^{42}$.

Para concluir, podemos dizer que em relação ao texto dos Elementos, especificamente ao conteúdo matemático, Araújo Guimarães segue fiel ao que Legendre escreveu. Não identificamos

\footnotetext{
${ }^{40}$ Gallica, C. F. M. Marie, Historie des Sciences Mathématiques et physiques, datada de 1885 e a respeito de Arquimedes, consultar, J.ean-Étienne Montucla, Histoire dês mathématiques, de 1758.

${ }^{41} \mathrm{Ibid}, .4$.

${ }^{42}$ É possível acessar e baixar no endereço http://gallica.bnf.fr/ as edições das obras Éléments de Geométrie e do Traité de Trigonométrié de Adrien Marie Legendre de 1794 e 1817.
} 
evidências de inclusões ou alterações que o tradutor tenha realizado. Devemos ressaltar que Araújo Guimarães teve o cuidado de incluir apenas comentários em relação às palavras empregadas na tradução, de modo a não gerar dúvida ao leitor. Como verificamos na "Nota I", em relação à utilização das palavras aresta ou gume, Araújo Guimarães disse que o autor empregou a expressão faite, e ele se serviu do termo "aresta" por ser mais comum, porém se alguém preferir poderia empregar a expressão "gume". 43

Seguimos com a parte destinada a trigonometria. Conforme mencionamos o Tratado de Trigonometria foi incluído a partir da primeira publicação de 1794. A publicação de 1804 (5a edição) que Araújo Guimarães disse ter utilizado para realizar a tradução, continha, portanto, o Tratado de Trigonometria.

Retrocedendo um pouco em relação às discussões que realizamos, para que possamos fundamentar nossas argumentações relativas à tradução de Araújo realizou na parte destinada a trigonometria, devemos lembrar que Araújo Guimarães esteve em Portugal entre 1791 e 1805, retornando ao Brasil em 1805.

Como também dissemos no capítulo anterior, sua formação inicial foi no Brasil numa escola jesuíta e, seguindo para Portugal, teve uma formação matemática que concebia a divisão da circunferência em 360 partes, correspondendo a $1^{\circ}$ grau cada parte. No entendimento de Araújo Guimarães a partição da circunferência no sistema decimal era uma peculiaridade francesa. ${ }^{44}$

Voltando ao segundo capítulo desse trabalho, mostramos que Araújo Guimarães, ao receber a designação para a tradução da obra de Legendre, dada por Dom Rodrigo de Souza Coutinho, disse ter percebido que os estudantes sentiriam dificuldades em operar com a divisão do primeiro quarto do ciclo trigonométrico em um sistema decimal e sugeriu adequações. Araújo Guimarães na Introduccão do Traductor disse que:

No Prefacio da Geometria reservei, para este lugar dar conta das mudanças, que fui obrigado a fazer, em razão de seguir o A. a nova divisão o circulo. Ao prazer de comprir aquella promessa, se ajunta a satisfação de obedecer ao Respeitavel Preceito de hum Ministro tao illustre pelo seu Patriotismo e constante pratica de todas as virtudes, como pela vastidão de seus conhecimentos, e pelo afincado amor as sciencias. Ao traduzir as primeiras paginas senti a difficuldade que terião os Discipulos em abraçar hum systema inteiramente estranho, e do qual, já pela construcção das Taboas mais vulgares, já por ser aquella innovaçáo particular aos Francezes, deviâo abrir mâo, e darem-se á applicação de outros exemplos analogos ao systema ordinário ${ }^{45}$.

Para o tradutor, a "Grande Escola Europeia” de produção de obras destinadas ao ensino de matemática, a escola francesa, favoreceu que Legendre reconhecesse a divisão da circunferência em 400 partes. Para o tradutor, a referência foi o trabalho intitulado Rapport Sur Le Choix Dúne Unité de Mesure assinado por Borda, Monge, Condorcet, Lagrange e Laplace, em 1791. Araújo Guimarães, porém, se colocou como alguém que tinha por obrigação promover algumas alterações, evitando causar problemas aos seus estudantes.

Para cortar este embaraço [da divisão do círculo em 400 partes], lembro o facil expediente de ajuntar ao Texto escrupulosamente conservado (como he

\footnotetext{
${ }^{43}$ Adrien Marie Legendre. Éléments de Géométrie, avec des notes - 12a .ed. (Paris: Firmin Didot) (1794) bttp://gallica.bnf.fr/ ark:/ 12148/bpt6k.5720354t.r=Adrienmarie+Legendre.langEN [consultado em 13/11/2010].

${ }^{44}$ Manoel Ferreira Araújo de Guimarães, Tratado de Trigonometria, (Rio de Janeiro: Impressão Régia, 1809)

45 Ibid.
} 
dever de hum Traductor) a reducção dos gráos e minutos, referidos ao angulo recto ou ao quadrante, dividido em 90 partes ou gráos, e fechar entre parenthesis estar educção: assim $50^{\circ}$ (a $45^{\circ}$ ) quer dizer que o arco ou o angulo de que se trata contém $50^{\circ}$ da nova divisão ou $45^{\circ}$ da antiga. Mas cumpria em primeiro lugar e as vantagens de húma e outra divisão, e as regras para passar com facilidade de hum a outro systema. ${ }^{46}$

O tradutor justificou as alterações que promoveu no Tratado de Trigonometria tendo como referência o número de divisores de 360 e 400 e no fato de que, a divisão em 360 partes, era uma tradição sedimentada pelos antigos geômetras desde os primeiros trabalhos publicados acerca da divisão do círculo pelos referindo-se assim, no nosso entendimento, aos gregos antigos. ${ }^{47}$

Araújo Guimarães seguiu com suas considerações relativas ao que representava na tradição histórica herdada pelos gregos o sistema de divisão do ciclo trigonométrico, o que em nosso entendimento, revela o conhecimento das ideias dos gregos antigos, entre eles Euclides e seus Elementos, que permearam à sua formação em Matemática.

Quando os primeiros Geometras tiveráo em vista a divisão do circulo, procurarão hum numero que tivesse muitos divisores. O numero 360 offerecia esta vantagem; porque tem 24 divisores; e repartido o circulo em quatro partes ou quadrantes, cada hum continha 90 destas partes que chamaráo grão, numero que tambem fornece muitas partes aliquotas — partírio cada grão, em 60 partes a que chamárão minutos, cada minuto em 60 segundos, \&c. ${ }^{48}$

Vemos nesse trecho o seu entendimento no que se refere à ciência matemática. Voltemos um pouco ao que dissemos em relação às experiências acumuladas por Araújo Guimarães para que ele concebesse o trabalho com o sistema de partição em 360 partes. Acerca da experiência acumulada, mencionamos que a tradução realizada por Araújo Guimarães em 1800, quando ainda era aluno da Real Academia da Marinha em Portugal, da obra Curso Elementar e Completo de Mathemáticas-puras, Nicolas Louis La Caille (1713-1762), em que da página 186 a 243, destinada aos Elementos de Geometria, a medida do ângulo reto era $90^{\circ} .{ }^{49}$

Há também, na obra de Silvestre François Lacroix (1765-1843) intitulada Traité élémentaire de trigonométrie rectiligne et sphérique et d'application de l'algèbre à la géométrie [Text eimprimé], observações em relação à partição do $1^{\circ}$ quadrante. Não nos esqueçamos que Lacroix, ao que nos pareceu, era o autor de Geometria preferido de Araújo Guimarães. Na obra que consultamos de Lacroix de 1807, ele adotou o sistema decimal, mas destacou que reconhecia a importância da partição do

\footnotetext{
${ }^{46}$ Ibid, 1.

${ }^{47}$ Não é objeto dessa investigação a história de como o sistema de partição da circunferência em 360 partes se estabeleceu, sendo a medida fundamental de um ângulo igual a $1^{\circ}$. Contudo, de acordo com os levantamentos que realizamos, há uma menção recorrente ao trabalho do grego Hiparco de Nicéia (180-125 a.C.) com sua tabela de cordas, que trouxe contribuições para que tal sistema prevalecesse como base. Há, ao menos, duas outras explicações. Uma delas considera que o número teria sido estabelecido por uma civilização que acreditava ser a terra o centro do universo e cujo calendário teria 360 dias. Para essa civilização, o Sol se deslocava um grau por dia, totalizando os 360 graus da circunferência. Outra explicação é a de que os babilônios usavam 60 como a base para seus cálculos. Por esse motivo, os gregos teriam dividido o raio do círculo em 60 partes. Como já seria conhecido que o comprimento da circunferência equivaleria a 2. $\pi . \mathrm{r}$ - duas vezes $\pi$ vezes o raio - e que $\pi$ valia aproximadamente 3 , então teria se estabelecido que a circunferência teria 360 graus (2 x 3 x 60 =360). Nos limitamos a dizer que partindo do trabalho de Boyer, História da Matemática, pp.115-135, podemos identificar outras fontes que tratam especificamente de abordar as formas de medir a circunferência, como por exemplo: Paul Tannery, "Recherches sur l'histoire de l'astronomie ancienne", Gallica, http:/ / gallica.bnf.fr

${ }^{48}$ Manoel Ferreira Araújo de Guimarães, Tratado de Trigonometria, (Rio de Janeiro: Impressão Régia, 1809), 2.

${ }^{49} \mathrm{La}$ Caille, N. L., Curso Elementar e Completo de Mathematicas-Puras, Manoel Ferreira de Araújo Guimarães trad. Lisboa: (Na Officina Patriarcal de João Procópio Correa da Silva, 1800) (186-243)
} 
quadrante em 90 partes. Nesse trabalho, porém, do modo como o autor encaminhou a organização do texto, o sistema decimal adotado não teria importância..$^{50}$

Araújo Guimarães escreveu que o número 360 oferecia a vantagem de possuir 24 divisores, com a divisão da circunferência em quatro partes, com cada parte composta por $90^{\circ}$, já que a unidade fundamental de medida do ângulo equivaleria a um grau. O tradutor argumentou também em relação à vantagem em se considerar o antigo sistema, pois, no primeiro quadrante da circunferência, os números 60 e 90 seriam números da primeira centena com uma quantidade considerável de submúltiplos. ${ }^{51}$

Araújo Guimarães, porém, elogiou a opção francesa em se trabalhar com 100 partes, ou $100^{\circ}$, no primeiro quarto da circunferência ao invés de $90^{\circ}$, pois a base de numeração passaria a coincidir com a base dez, ou seja, o ângulo reto teria 100 graus; cada grau, cem minutos e cada minuto, 100 segundos. O tradutor demonstrou entender a opção que Legendre fez. Para ele, a opção francesa traria benefícios, pois facilitaria as transformações entre os graus, os minutos e os segundos, uma vez que estes estariam expressos em uma base decimal, pois cada minuto nesse sistema representa 0,01 do grau e cada segundo 0,01 do minuto ou 0,0001 do grau, o que compensaria a perda em números de divisores, que ocorrera com a opção pela base decimal em detrimento da partição em $360^{\circ}$ para a circunferência. Vejamos o que disse a respeito Araújo Guimarães:

Por esta mudança perderão a vantagem dos divisores, tendo o número 360 mais 9 divisores do que 400, 90 mais 3 do que 100, e 60 tantos como 90. Todavia esta perda foi muito compensada pela facilidade do calculo, porque sendo cada minuto 0,01 do grão, e cada segundo 0,01 de minuto, ou 0,0001 do grão, estas grandezas se calculão como inteiros e decimaes. Por exemplo $8^{\circ} 35$ '25" desta divisão equivale a $8^{\circ} 35^{\prime} 25^{\prime \prime}$, ou a $8^{\circ}, 3525.5^{2}$

As compensações das perdas, no entendimento de Araújo Guimarães, poderiam ser um argumento satisfatório, contudo ele deixou mostras de que o motivo relevante para a opção francesa deveria ter raízes mais profundas. Em suas considerações ele apontou para os ideais iluministas, que permeavam o pensamento francês do século XVII:

Ésta divisão era a unica seguida até o fim do século passado, época fecunda em revoluções estrondosas. O espírito de innovação chegou até as sciencias, e só então deixou de ser funesto. Limitando-me ao objecto que presentemente me incumbe, direi que os Francezes (e o primeiro lugar he devido a Borda) dividirão o quadrante, ou a medida do ângulo recto, em 100 gráos, o gráo em 100 minutos; e assim por diante. Por esta mudança perderão a vantagem dos divisores, tendo o numero 360 mais 9 divisores do que 400, 90 mais 3 do que 100 , e 60 tantos como 90.53

$\mathrm{Na}$ mesma nota do tradutor, vemos a menção às "revoluções estrondosas" que atingiram as ciências, uma menção que entendemos ter indicações do conhecimento acerca da Revolução Francesa. Dentre outras questões, o tradutor trouxe a proposta de unificação do sistema de medi-

\footnotetext{
50 Antonio Joaquim Damasio, Biographia dos Brasileiros Distinctos por Armas, Lettras, Virtudes e etc., (Rio de Janeiro: IHGB, 1881),372-7; Antônio Luiz Porto e Albuquerque, “A Academia Real dos Guardas-Marinha" História Naval Brasileira, vol. II (Rio de Janeiro: Serviço de Documentação-Geral da Marinha, 1979), 352-6; Lacroix, Traité Elémentaire de Trigonometrie Rectiligne et Sphérique, et d'application de L'Algebre a La GGeométrie, (aris, Courcier, 1810),16-7;

51 Vemos que essa consideração é fundamentada na evidência de que os divisores de 360 são vinte e quatro, a saber: $1,2,3$, $4,5,6,8,9,10,12,15,18,20,24,30,36,40,45,60,72,90,120,180$ e 360.

${ }_{5}$ Manoel Ferreira Araújo de Guimarães, Tratado de Trigonometria, (Rio de Janeiro: Impressão Régia, 1809$), 2$.

53 Ibid.
} 
da na base decimal. E sentenciou em outro trecho que as nações mais iluminadas não adotaram ainda a opção francesa por entenderem que tal mudança poderia trazer confusão em relação às produções mais expressivas que tradicionalmente eram utilizadas para o ensino de matemática. Nas palavras do tradutor:

As nações illuminadas não tem ainda adoptado semelhante mudança, não pelos frívolos motivos que retardarão entre algumas a admissão da correcção Gregoriana, mas por causas que me não cumpre averigoar, talves tendo lugar entre ellas a confusão que se experimentaria nos livros anteriormente escritos, livros de merecimento mais decidido. ${ }^{54}$

Para Araújo Guimarães as nações iluminadas eram todas as que receberam as luzes, que saíram da ignorância, no sentido dado para a expressão àquela época. Nações que, como a França, apenas por uma questão de tempo e não por motivos frívolos, adotariam o sistema decimal como referência, inclusive para a correção das publicações destinadas ao ensino de matemática baseadas nos gregos. ${ }^{55}$

Como pudemos verificar Araújo Guimarães praticamente reescreveu o tratado de trigonometria de Legendre. Ele apontou como deveria ser relacionada à medição da circunferência em $360^{\circ} \mathrm{em}$ relação à proposta de Legendre de medi-la como $400^{\circ}$. Isso impunha que o estudante pensasse, por exemplo, no complemento de um ângulo com base na medida do ângulo reto que era igual a $100^{\circ}$. Assim:

O complemento de hum ângulo ou de hum arco he o que fica quando se subtrahe esse ângulo ou esse arco de $100^{\circ}$. Assim hum ângulo de $25^{\circ} 40^{\prime}$ tem por complemento $74^{\circ} 60^{\prime}$, hum ângulo de $12^{\circ} 4^{\prime}$ ' $62^{\prime \prime}$ tem por complemento $87^{\circ} 95^{\prime} 38^{\prime \prime}$.

* Na antiga divisão chama-se complemento de hum arco ou de um ângulo o que falta a esse arco ou a esse angulo para ser de $90^{\circ}$. Assim o complemento de hum angulo de $12^{\circ} 45^{\prime} 32^{\prime \prime}$ he o angulo de $77^{\circ} 14^{\prime} 28^{\prime \prime}$, o complemento de hum arco de $67^{\circ} 12$ '26" he um arco de $22^{\circ} 47^{\prime} 34^{\prime \prime}$. *

Em geral, sendo $\mathrm{A}$ hum ângulo ou um arco qualquer, e $q$ o quadrante, $q-A$ he o complemento desse ângulo ou desse arco. Donde se vê que se o ângulo ou o arco de que se trata exceder a $q$, o seu complemento será negativo. Deste modo o complemento de $160^{\circ} 84^{\prime} 10^{\prime \prime}$ he $-60^{\circ} 84^{\prime} 10^{\prime \prime}$, (e no systema antigo o complemento de $120^{\circ} 14^{\prime} 44^{\prime \prime}$ he $\left.-30^{\circ} 14^{\prime} 44^{\prime \prime}\right)$. Nesse caso o complemento tomado positivamente, seria a quantidade que se deveria tirar do ângulo ou do arco dado, para que o resto fosse igual ao quarto da circunferência. ${ }^{56}$

Araújo Guimarães colocou entre parênteses, no texto da tradução, as partes alteradas ao tratar da relação entre o novo sistema e o antigo. O tradutor marcou a inserção de novos exemplos e advertências no texto com o sinal $(*)$, o que, segundo ele, facilitaria a identificação dos pontos assumidos como inseridos no texto de Legendre.

$\mathrm{Na}$ parte destinada à trigonometria podemos afirmar que Araújo Guimarães praticamente teve de adequá-la ao seu propósito de conceber a partição da circunferência como era tradição na

\footnotetext{
54 Ibid.

${ }^{55}$ Luiz Maria da Silva Pinto, Diccionario da Lingua Brasileira, (Ouro Preto, MG: Typographia de Silva, 1832), $26-1132$.

${ }^{56}$ Manoel Ferreira de Araújo Guimarães, Introducção do Traductor a Tratado de Trigonometria (Rio de Janeiro: Imprensa Régia, 1809),3.
} 
qual ele se formou e que prevalecia em Portugal, a de $360^{\circ}$ para medir uma volta na circunferência. Quanto ao conteúdo, relativamente às linhas trigonométricas e as relações para os triângulos retilíneos ou esféricos não sofreram nenhuma alteração. Porém, as tabelas com as medidas dos ângulos, as transformações para medir o ângulo reto e outros ângulos e as sugestões para a realização das transformações de um para o outro sistema foram dadas por Araújo Guimarães, o tradutor e, nesse caso também, o editor. ${ }^{57}$

Entendemos que nos resta, ainda, comentar algumas referências que foram fundamentais para a realização dessa investigação e que, de alguma forma serviram como fontes de consulta que nos guiaram até aqui. Vamos em outro momento trazer outras referências, em áreas como a história da imprensa no Brasil, da literatura, ou em documentos de época, ou muito próximos, que tratem de pessoas e fatos que favoreçam uma releitura relativa a identidade de Araújo Guimarães.

\section{Considerações Finais}

Finalizamos deixando alguns apontamentos que consideramos essenciais para esta parte. Há alguns aspectos que devemos considerar de início, pois têm relação com o ensino de Matemática no Brasil no início do século XIX. Um dos aspectos, diz respeito à necessidade de se formar Engenheiros habilitados a construir fortificações em pontos mais frágeis do território brasileiro para evitar as invasões, proceder à preparação de cartas geográficas que facilitariam as demarcações de terras, quando da penetração no interior do território, além de estabelecer núcleos que seriam habitados por pessoas, formando as vilas. Outro aspecto a destacar, é que não havia no Brasil a formação universitária, pois a preocupação portuguesa era de que o povo, tendo sido educado, poderia organizar-se de modo a lutar pela emancipação da colônia.

Desse modo, vemos que para Portugal tudo o que se referisse à proteção e ao domínio do território brasileiro tinha prioridade. Por outro lado, quando se referia ao ensino superior a mesma não existia. $\mathrm{Na}$ verdade, o que havia era a proibição para sua instalação em terras brasileiras. Em nosso entendimento, o fato de não haver a preocupação com a formação superior de técnicos poderia ser preponderante para que houvesse dificuldades em preservar o território e ampliá-lo. Ou ainda, a preocupação com uma possível emancipação poderia trazer dificuldades para preservar, sob o domínio português, o espaço territorial da colônia brasileira.

A pesquisa que realizamos permite afirmar que Araújo Guimarães contribuiu, inclusive, para que no final do século XIX surgissem as obras consideradas como as que originalmente foram produzidas em terras brasileiras para o ensino de Matemática. Obras que entendemos merecerem estudos um pouco mais detalhados de modo a buscar as relações com as traduções que foram produzidas nos primeiros anos. Assim, há espaço para pesquisas relativas à História da Matemática no Brasil que busquem olhar para os possíveis desdobramentos das traduções realizadas por Araújo Guimarães nas publicações tidas como genuinamente brasileiras ${ }^{58}$.

A partir de tudo que investigamos, relativo a Araújo Guimarães, podemos propor que seu trabalho não pode ser deixado à margem da história da matemática brasileira, uma vez que suas contribuições deixaram reflexos nas produções destinadas ao ensino da Matemática, entre o final do século XIX e início do século XX.

Entendemos que Araújo Guimarães está à margem, nos textos que consultamos em relação à História da Matemática brasileira, basicamente porque os autores desses textos não têm se preocupado com a análise de documentos que tragam elementos da vida e obra dos autores, possí-

\footnotetext{
${ }^{57}$ Não vamos nos alongar nas considerações relativas as edições que Araújo Guimarães deixou no texto traduzido. Deixamos para o leitor as seguintes indicações: Guimarães, Tratado de Trigonometria, pp. 7-126.

58 Wagner Rodrigues Valente, Uma História da Matemática Escolar No Brasil (1730-1930) (São Paulo, Editora Annablume, 1999),129-53.
} 
veis relações entre fatos determinantes em um período histórico, ou por não entenderem que a tradução de Araújo Guimarães, assim como de tantos outros, fazia parte de um plano de governo da família Real instalada no Brasil a partir do início do século XIX.

Pensamos que Araújo Guimarães deva ser entendido como alguém que deixou para a História da Matemática brasileira, muito mais que algumas traduções. Seu domínio do Latim, do Francês, do Inglês e do Grego, favorecia que realizasse traduções para o português adequando termos e ideias, sem comprometer a produção original. Ele era um tradutor experiente que, conforme levantamos, atuou de 1800 até 1824, ou seja, 24 anos, aproximadamente. Ele traduziu do francês para o português as obras destinadas ao ensino de Matemática, de autores como Lacroix, Legendre, Euler, La Caille, dentre outros. Como vimos, especificamente, nas obras de Legendre as quais analisamos, o tradutor tinha a dimensão do que era o ensino de matemática à sua época, pois percebendo que seus alunos sentiriam dificuldades em operar com o sistema de medida decimal, estabelecido por Legendre no Tratado de Trigonometria, cuidou de promover adequações. Pudemos perceber, em seus escritos, uma preocupação para com os seus alunos. Para ele era fundamental que o aluno compreendesse o que o texto pretendia. Essa preocupação foi caracterizada pela passagem contada por Damasio, em que Araújo Guimarães combinou abordagem de alguns autores para ensinar determinado assunto matemático ${ }^{59}$.

Relativamente ao alcance das traduções das obras de Legendre, como pretendemos considerar no próximo trabalho, caberia uma análise da relação entre as chamadas produções inéditas no Brasil e as traduções deixadas por Araújo Guimarães. ${ }^{60}$

Em relação às dificuldades para a realização desta investigação, podemos dizer que não foram poucas. Há instituições que lutam para preservar arquivos com documentos relativos à História do Brasil. As condições climáticas brasileiras e o modo como são guardados os documentos, principalmente os manuscritos, como os que encontramos no Arquivo Nacional no Rio de Janeiro, nos levam a pensar que em alguns anos não teremos mais tais documentos à disposição devido à degradação do acervo. Mesmo assim, somos otimistas e acreditamos que alguma providência será tomada. Notamos a intenção de alguns em organizar e preservar os acervos e buscar verbas, por projetos, para o investimento em digitalização e preservação dos documentos, principalmente os responsáveis diretos pelos arquivos. ${ }^{61}$

Dessa forma, são ainda muitos os possíveis desdobramentos desta pesquisa. Acreditamos ser necessário um estudo referente à dimensão social das contribuições de Araújo Guimarães para a história da imprensa no Brasil.

A investigação, realizada para a produção deste texto, mostra a importância de se ater a documentos, investigá-los e analisá-los. Abra-se, desse modo, um campo para que se estabeleçam pesquisas que reavaliem os apontamentos repetidos e as ideias sedimentadas há tempos sobre a História da Matemática brasileira.

Para a elaboração deste texto tivemos que optar por algumas questões em detrimento de outras, que também são tão merecedoras de atenção. Porém, entendemos que as outras questões, neste não incluídas, serão abordadas em estudos futuros e que estão previstos no projeto de pósdoutoramento, que desenvolvemos junto a Universidade de São Paulo.

\footnotetext{
${ }^{59}$ Ibid, 372-5.

${ }^{60}$ Desdobramentos da produção de M.F.A.G, por exemplo, nas páginas 149 e seguintes, que dá destaque à produção de Cristiano Ottoni que confessa ter consultada as traduções da obra de Legendre.

${ }^{61}$ Há documentos como, por exemplo, o dossiê relativo à carreira militar de Araújo Guimarães, que não foi localizado. Parece ter havido um extravio quando foi transferido da Universidade Federal do Rio de Janeiro para o Arquivo Nacional, isto em 1973.
} 